\title{
Numerical Simulation of Foundation Treatment of Liquid Soil Materials
}

\author{
Yong YANG ${ }^{1 \mathrm{a}}$, BaoBing ZHU ${ }^{2 \mathrm{~b}}$, Juanjuan $\mathrm{CHEN}^{3 \mathrm{c}}$, Chongwei HUANG ${ }^{3 \mathrm{~d}^{*}}$, Zhiyuan FENG ${ }^{1 \mathrm{e}}$ \\ ${ }^{1}$ Shanghai Road and Bridge (Group) Co., Ltd, Shanghai, China \\ ${ }^{2}$ Zhejiang Mingde Construction Co., Ltd, Hangzhou, China \\ ${ }^{3}$ Department of Transportation Engineering, University of Shanghai for Science and Technology, Shanghai, China
}

\begin{abstract}
As a new type of backfill material for abutment back treatment, there is still a gap in theoretical research and practical application. Aiming at the research on the treatment effect of the new backfill material liquid soil, this paper uses the finite element software for numerical simulation, comprehensively compares and analyzes the settlement and deformation characteristics of the new backfill material liquid soil and the conventional soil under the same working condition, and evaluates the treatment effect according to the calculation results; The results show that under the action of self weight load and traffic load, the overall settlement of both sides presents a similar distribution. In the horizontal direction, the settlement gradually increases from the near platform back to the far platform back. In the vertical direction, the settlement first increases and then decreases. Moreover, the road settlement under the action of vehicle load is larger than that under the action of self weight load only. However, the settlement of liquid soil backfill is far less than that of conventional soil backfill. Using liquid soil as backfill material can reduce the harm and economic loss caused by settlement to a certain extent.
\end{abstract}

\section{Introduction}

With the continuous growth of the scale of infrastructure construction, a large number of new bridges and expressways, the problem of vehicle bump at the bridge head becomes more and more serious. It is due to the uneven settlement of the Subgrade after the connection between the subgrade and the abutment, resulting in the settlement contrast between the abutment and the top surface of the subgrade, and finally forming the problem of vehicle bump at the bridgehead ${ }^{[1]}$. Many countries and many independent research institutions have carried out a large number of special investigations on this problem.

Reid and Buchanan studied the application of pile supported reinforced soil composite foundation technology to the treatment of abutment back fill in the mid-1980s. The results show that the pile supported reinforced soil composite foundation can significantly reduce the differential settlement between the road and bridge transition sections ${ }^{[2]}$.

In North America, Japan and some European countries, geogrids are used for subgrade reinforcement to reduce the settlement difference of road bridge transition section and solve the bump phenomenon at the bridge head ${ }^{[3]}$.

In 1972, the Norwegian Road Research Institute first used polystyrene as backfill material, and found that EPS with light and high strength can be used as backfill

\footnotetext{
a416993550@qq.com

b27063207@qq.com

c144828337@qq.com

d*Corresponding author: hcwei@126.com

e1925099319@qq.com
}

material in the construction of road and bridge transition section to reduce the settlement of embankment fill after abutment, and then reduce the difference between abutment back and abutment embankment fill ${ }^{[4]}$.

From the above research, it can be found that reducing the settlement of backfill soil behind abutment is one of the main ways to solve the problem of vehicle bump at bridge head. At present, the problem of bump at bridge head is more prominent due to the heavy soil itself and the poor soil compaction effect caused by the small working face of abutment back pressure. On the other hand, the use of EPS and other new lightweight materials as the rebound material of the back of the abutment has a high cost, and large-scale construction will greatly increase the cost of the project.

According to the latest literature abroad, a new type of backfill material, controlled low strength material (CLSM), is being used in road backfill in the United States and other countries. It is a new material with light weight, low strength and can replace the traditional backfill material $^{[5]}$. The liquid soil material studied in this paper is a kind of mixed material with better fluidity, workability and road performance. In the practical application of abutment backfill, it plays an important role in the uneven settlement of subgrade, solving the problem of vehicle bump at bridge head and improving the quality of road construction.

However, the research and application of liquid soil 
in China is still very few, and its specific application effect is still in the exploratory stage, so it is necessary to carry out in-depth research on the treatment effect of liquid soil, so as to improve the domestic research system of liquid soil. Therefore, through three-dimensional finite element simulation, this paper establishes the road model after liquid soil backfill; Compared with the finite element model under the conventional soil backfill, from the overall settlement distribution analysis, to provide guidance for the actual construction parameters.

\section{Establishment of finite element model}

\subsection{Basic parameters}

For the sake of simplicity, the linear elastic constitutive model is adopted in the finite element model, and the parameters are shown in Table 1.

Tab 1. model parameter

\begin{tabular}{llll}
\hline position & $\gamma_{d}$ & $\mathrm{E}$ & $v$ \\
\hline Surface course & 21.4 & $2.1 \mathrm{e}+6$ & 0.3 \\
abutment & 20.0 & $2.34 \mathrm{e}+7$ & 0.15 \\
Approach slab & 20.0 & $2.34 \mathrm{e}+7$ & 0.15 \\
Embankment filling & 18.3 & $2 \mathrm{e}+4$ & 0.40 \\
Conventional soil behind abutment & 14.0 & $3.0 \mathrm{e}+4$ & 0.30 \\
Liquid soil behind abutment & 13.5 & $4 \mathrm{e}+4$ & 0.30 \\
\hline
\end{tabular}

\section{2 geometric parameters}

width is $24 \mathrm{~m}$, the total height is $18 \mathrm{~m}$, in which the pavement thickness is $0.7 \mathrm{~m}$, and the height of

The numerical simulation analysis adopts the strain embankment fill and abutment backfill is $5.3 \mathrm{~m}$. model shown in Fig 1. The size of the model is: the total

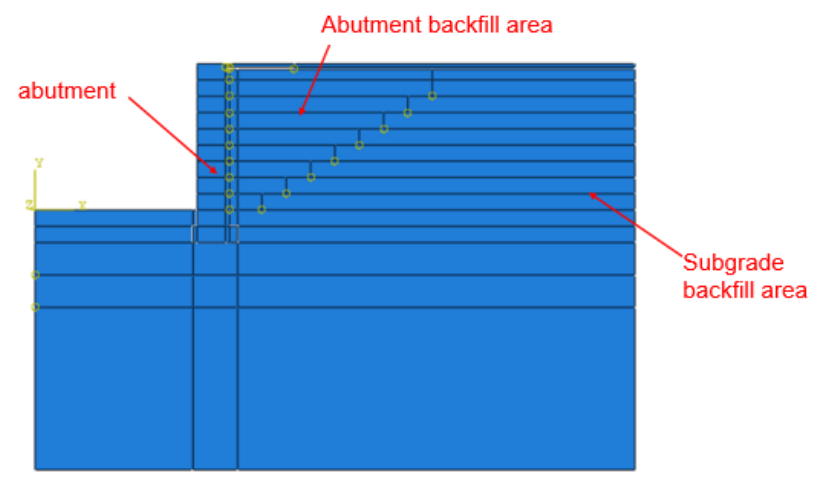

Figure 1. Geometric dimension of numerical model

\subsection{Load application}

In this paper, the self weight load can be calculated by finite element software. According to the actual situation of the existing project, Han and GABR ${ }^{[6]}$ think that the equivalent load of 10KPA is used to replace the effect of traffic load on the embankment pavement, and the calculated deformation results are more consistent with the actual situation. Therefore, in order to simplify the calculation process, the vehicle load is equivalent to 10KPA static load in this paper.

\section{4 boundary conditions and mesh generation}

The boundary conditions are as follows: the foundation bottom is set with $\mathrm{X}$ and $\mathrm{Y}$ direction constraints; The left and right sides of the foundation are set with $\mathrm{X}$-direction constraints; The right side of embankment is constrained in X direction; The $\mathrm{x}$-direction constraint of abutment. The contact between the right side and bottom of the abutment and the backfill material and the foundation is considered $^{[7]}$.

Grid element division: considering the consolidation behavior of soil, cpe $4 p$ grid structure is adopted for soil foundation; Cpe4r grid structure is adopted for embankment filling layer, abutment backfill layer and abutment.

\section{Analysis of numerical simulation results}

The overall settlement calculation results of liquid soil and conventional soil as abutment backfill are shown in Fig 2 and Fig 3.

It can be seen intuitively that under the foundation condition, the overall settlement of the model presents a similar distribution, whether it is conventional soil backfill or liquid soil backfill. No matter under the action of self weight load or traffic load, the overall settlement distribution of the model is gradually increasing from the near platform back to the far platform back in the horizontal direction (that is, the blue area in the 
distribution diagram), and it shows a trend of first increasing and then decreasing in the vertical direction.
However, the settlement of liquid soil backfill is significantly smaller.

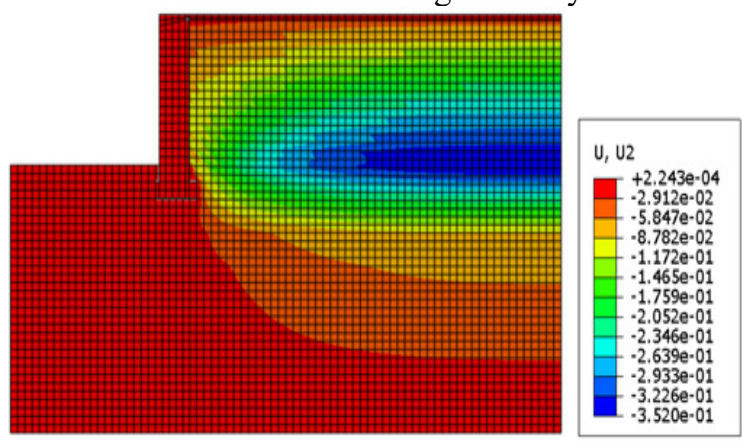

a) Under self weight load

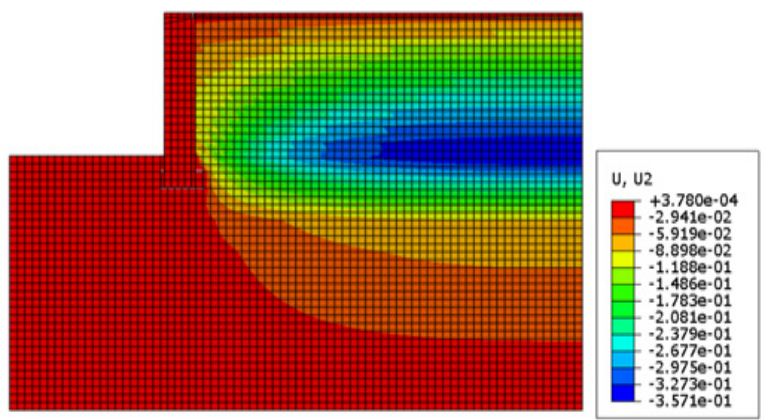

b) Under the action of traffic load

Figure 2. Settlement distribution of conventional soil abutment backfill

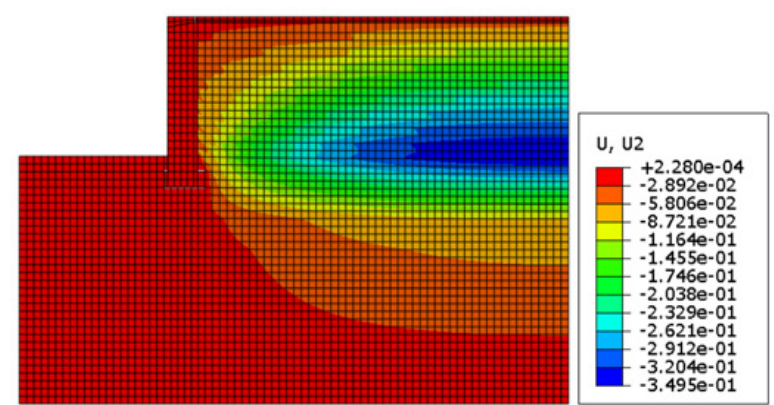

a) Under self weight load

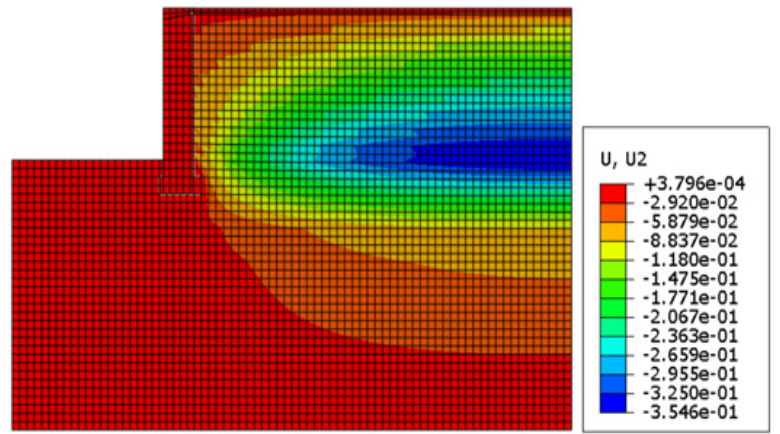

b) Under the action of traffic load

Figure 3. Settlement distribution of liquid soil backfill behind abutment

In the horizontal direction, due to the uniform distribution of load, the external force of each node at a certain time can be regarded as consistent. As a fixed body, the abutment is restrained vertically to simulate the low settlement of the actual abutment. However, there is contact friction between the abutment and the backfill at the back of abutment. Under the same external stress, the settlement is bound to be smaller, thus forming the transverse settlement distribution as shown in the above two figures.

In the vertical direction, when the corresponding additional stress acts on the whole model, the surface layer is made of asphalt material, and its modulus is relatively high, so the settlement is small. When the stress is transferred to the soil foundation, the additional stress generated by the self weight load increases 
gradually with the depth, and the modulus of the backfill is the same, which leads to the phenomenon that the settlement value gradually increases, which is shown as the transition from red to blue in the figure.

It can be seen from Fig. 2 and Fig. 3 that the settlement distribution laws of conventional soil and liquid soil under self weight load and driving load are consistent, but there is still a slight difference in quantity. For conventional soil, the minimum value is $2.243 \times$ The maximum value is $0.352 \mathrm{~m}$; The minimum value is 3.780 under vehicle load $\times$ The maximum is $0.3571 \mathrm{~m}$. For liquid soil, the minimum settlement is $2.280 \times$ The maximum is $0.3495 \mathrm{~m}$; The minimum value is 3.796 under vehicle load $\times$ The maximum is $0.3546 \mathrm{~m}$. This shows that the road settlement under the action of vehicle load is larger than that under the action of self weight load, which is inevitable. The settlement of liquid soil is smaller than that of conventional soil.

\section{Conclusion}

This paper mainly analyzes the settlement deformation of different backfill materials (conventional soil and liquid soil) under the same working conditions. The main conclusions are as follows:

(1) The minimum value is $2.243 \times$ The maximum value is $0.352 \mathrm{~m}$; The minimum value is 3.780 under vehicle load $\times$ The maximum is $0.3571 \mathrm{~m}$. It shows that the settlement of road under the action of vehicle load is larger than that only under the action of self weight load.

(2) The minimum settlement is 2.280 under the self weight of liquid soil $\times$ The maximum is $0.3495 \mathrm{~m}$; The minimum value is 3.796 under vehicle load $\times$ The maximum is $0.3546 \mathrm{~m}$. This is consistent with the law and principle of conventional soil for abutment backfill.

(3) From the above numerical simulation results, it can be seen that the settlement of liquid soil is small, and it can reduce the harm and economic loss caused by settlement to a certain extent as backfill material. It can effectively solve the differential settlement between subgrade and structure and difficult backfill construction, reduce the bumps and vibration caused by settlement of vehicles, reduce the risk of road operation and improve the quality of road operation. It can provide a new scheme for the research of filling materials.

\section{Reference}

1. MENG Z.J., (2020) Research on Causes and prevention measures of vehicle bump at bridgehead [J]. Traffic world, (12): 64-65.

2. WANG, F. (2008) Field test and finite element analysis of pile supported reinforced soil composite foundation [D]. Zhejiang University.

3. LU R.N. (2005) Numerical simulation of interaction between Geogrid and soil and its engineering application [D]. Southwest Jiaotong University.

4. ZHANG S.G., FANG J.H., JIANG B.H. (2017) Application of lightweight materials in highway bridge and culvert abutment backfill [J]. Qinghai transportation science and technology, (03): 110-112.

5. ACI Committee 229R, (1999) Controlled low strength materials(CLSM), ACI 229R - 99.

6. Zhang, J.H. (2006) Study on deformation characteristics and differential settlement control standard of Expressway Widening on soft soil foundation [D]. Southeast University.

7. Ge, Z.S, Huang, X.M., Zhang X.N., Gao J.(2006) Study on Application of ceramsite fly ash concrete in bridge abutment backfill [J]. Geotechnical mechanics, (11): 2076-20 